\begin{tabular}{|c|c|c|}
\hline & Int.J.Curr.Microbiol.App.Sci (2016) 5(10): 27-32 & \multirow{2}{*}{ 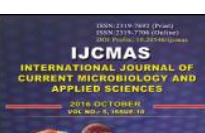 } \\
\hline & \multirow{4}{*}{$\begin{array}{l}\text { International Journal of Current Microbiology and Applied Sciences } \\
\text { ISSN: 2319-7706 Volume } 5 \text { Number } 10 \text { (2016) pp. 27-32 } \\
\text { Journal homepage: http://www.ijcmas.com }\end{array}$} & \\
\hline & & \\
\hline EXCELLENT & & \\
\hline PUBLISHERS & & wwwri.jicmas.com \\
\hline
\end{tabular}

Original Research Article

http://dx.doi.org/10.20546/ijcmas.2016.510.005

\title{
Chronic Obstructive Pulmonary Disease: Understanding and Promoting Healthy Lifestyle among Gond Tribe in Madhya Pradesh, India
}

\author{
Surendra Kumar*, M. Muniyandi, Dinesh Kumar, Maya Pandey, \\ Visheshwar Soan and S. Rajasubramaniam \\ National Institute for Research in Tribal Health (ICMR), Jabalpur, India \\ *Corresponding author
}

\begin{abstract}
A B S T R A C T
Keywords

Tobacco

consumption,

COPD, tribe,

marginalized

population,

India.

\section{Article Info}

Accepted:

12 September 2016

Available Online:

10 October 2016

Chronic Obstructive Pulmonary Disease (COPD) is an increasing cause of chronic morbidity and mortality around the world. Prevalence of COPD among ethnic populations is not well documented. To study the prevalence of COPD among the marginalized Gond tribes of Kundam Block of Madhya Pradesh state in central India, cross sectional survey was conducted amongst the Gond tribes of Kundam Block, during the years 2007 to 2009. Screening was done by medical officer based on the clinical signs and symptoms such as cough with mucus, breathlessness or dyspnoea and exhaustion. Stethoscope was used to identify wheezing or other abnormal chest sounds. A semi-structured questionnaire was used to collect information on socio-demographic and smoking habits. Prevalence of COPD among tobacco users was calculated. Of 2970 tobacco users screened, 23\% were tobacco smokers, $72 \%$ were tobacco chewers and 5\% used tobacco both for smoking and chewing. Prevalence of COPD was $9.4 \%$ among smokers, $0.6 \%$ among tobacco chewers and $6.5 \%$ among mixed users. The distribution of COPD cases was significantly more among smoking males, aged more than 45 years. The findings of the present study showed a direct correlation with tobacco use and COPD. There is a need of effective campaign for reducing smoking and counseling to lower the incidence of COPD.
\end{abstract}

\section{Introduction}

Chronic obstructive pulmonary disease (COPD) is a common lung disease; it is estimated to be the third leading cause of death by 2030 (WHO, 2013). Available literature on COPD prevalence, morbidity and mortality emanates from high-income countries. Even in these countries, accurate epidemiologic data on COPD are scattered and difficult to obtain.

However, it is reported that low and middle income countries also carry high burden of COPD with almost $90 \%$ death due to COPD
(Parvaiz, 2013). Moreover, in India vast gap in COPD burden among in different socioeconomic groups is present.

Tobacco use is one of the main risk factor for a number of chronic diseases, including cancer, lung and cardiovascular diseases. Further, tobacco use is most commonly found among poorest segments of the population and drains the household income away from daily living expenses. It is estimated that each year, the global tobacco epidemic kills nearly 6 million people, 
including more than 600,000 who die from exposure to second-hand smoke. By year 2030, more than 8 million people will succumb to tobacco related deaths mainly belonging to low- and middle-income countries. Differential exposures to this life style behavior will be largely associated with chronic diseases like heart disease, cerebro-vascular disease, COPD, and lung cancer. Despite, the knowledge of risk factors, much less attention has been paid to study tobacco related morbidities among socioeconomically vulnerable populations.

The National Institute for Research in Tribal Health, ICMR, Jabalpur, Madhya Pradesh has been undertaking studies to estimate the magnitude and kind of tribal health problems and to suggest corrective measures to improve their health and overall socioeconomic conditions. A community survey was conducted to estimate the prevalence of tobacco use among Gond tribe and demonstrated that about 65\% Gonds consume tobacco. As part of this survey, information on COPD among tobacco users was also collected. In this communication we describe the prevalence of COPD among the marginalized Gond population of Kundam Block of Madhya Pradesh, India.

\section{Methodology}

Cross sectional survey was conducted amongst the Gond tribes of Kundam Block during 2007 to 2009 to estimate the prevalence of tobacco use. ${ }^{3}$ This survey included clinical examination for tobacco related morbidities particularly COPD.

COPD was identified through spirometry, which measures how deeply a person can breathe and how fast air can move in and out of the lungs. This was done for any patient with symptoms of cough, sputum production, or dyspnea (difficult or labored breathing), and/or a history of exposure to risk factors for the disease. Further, WHO has mandated that in the absence of spirometry, the diagnosis of COPD should be made using all available tools. These include clinical symptoms and signs, such as abnormal shortness of breath and increased forced expiratory time etc. In the current study screening for COPD was done by medical officer based on clinical signs and symptoms, such as abnormal shortness of breath, wheezing and chest tightness and increased forced expiratory time. The confirmation of diagnosis based on clinical judgment based on a combination of history, physical examination and stethoscope was used to wheezing or other abnormal chest sounds.

A semi-structured, pre-coded questionnaire was used to collect information. Trained field investigators conducted the interviews after obtaining the informed consent from the respondents. The interviews were conducted at their homes post explanation of the purpose of the study, Respondents were informed about the confidentiality of the data collected and their right to withdraw from the study at any time. The interview included information related to household identification, demographic and socioeconomic characteristics and tobacco consumption. In addition, information regarding COPD was also collected by medical officer all identified COPD cases were counselled to quit tobacco, provided medicines and referred to nearest government health facility for further care and management. Data was scrutinized, and analyzed using the SPSS version 20.0 (SPSS Inc., Chicago, IL, USA).

This study was approved by Scientific Advisory Committee and Institutional Ethics Committee of National Institute for Research in Tribal Health (ICMR), Jabalpur. 


\section{Results and Discussion}

Among the 2970 (Male 1593; Female 1377) tobacco users screened, 681 (23\%) were tobacco smokers, $2134(72 \%)$ were tobacco chewers and $155(5 \%)$ were both tobacco smokers cum chewers. Sixty four smokers (9.4\%), 10 smoking cum chewers tobacco $(6.5 \%)$ and 13 chewers $(0.6 \%)$ suffered from COPD (Figure-1).

The age, sex, education and occupation of COPD patients is given in Table-1. Majority of COPD patients were males (98\%) with nearly $63 \%$ these men in the age group of over 45 years. The educational status was nearly same $48 \%$ vs $52 \%$ literate and illiterates respectively. Thus indicating the tobacco use was rampant irrespective of literacy status. Furthermore, majority (94\%) of COPD patients were daily wage labourers.

Traditionally, it is believed that tobacco smoking is the only major risk factor associated with the development of COPD and our findings are in sync with this belief.
Earlier studies both in India and Europe have documented these observations (Anderson, 1962; Singh, 2011). Earlier we have reported high tobacco smoking $(65 \%)$ among tribal populations. In a resource poor country like India, it is a challenge to curb the growing burden of COPD particularly among vulnerable segments of the population. Preventing the development of COPD therefore becomes the most economically viable option to reduce the burden of COPD. For this, we need to understand the risk factors that drive the development of COPD particularly in these communities.

The health consequences of smoking tobacco have been studied extensively which clearly demonstrated its causal role in COPD (Murray, 1997). Globally, COPD has emerged as the major cause of morbidity and mortality expected to become the $3^{\text {rd }}$ most leading and is cause of death and the $5^{\text {th }}$ leading cause of loss of 'Disability Adjusted Life Years' (DALYs) as per projection of the Global Burden of Disease Study (Jindal, 2012).

Table.1 Distribution of COPD cases according to their demographic and socio-economic status by their different kind of tobacco use

\begin{tabular}{|c|c|c|c|c|c|c|c|c|}
\hline & \multicolumn{2}{|c|}{ Smokers } & \multicolumn{2}{|c|}{ Chewers } & \multicolumn{2}{|c|}{ Mix users } & \multirow{2}{*}{$\begin{array}{c}\text { Total } \\
\text { No }\end{array}$} \\
\hline & & No & $\%$ & No & $\%$ & No & $\%$ & \\
\hline \multirow[t]{2}{*}{ Sex } & Male & 64 & 75 & 11 & 13 & 10 & 12 & 85 \\
\hline & Female & 0 & - & 2 & - & 0 & - & 2 \\
\hline \multirow[t]{2}{*}{ Age } & $\leq 45$ & 20 & 63 & 8 & 25 & 4 & 13 & 32 \\
\hline & $>45$ & 44 & 80 & 5 & 9 & 6 & 11 & 55 \\
\hline \multirow[t]{2}{*}{ Education } & Illiterate & 28 & 67 & 8 & 19 & 6 & 14 & 42 \\
\hline & Literate & 36 & 80 & 5 & 11 & 4 & 9 & 45 \\
\hline \multirow[t]{2}{*}{ Occupation } & Labour & 61 & 74 & 11 & 13 & 10 & 12 & 82 \\
\hline & Others & 3 & - & 2 & - & 0 & - & 5 \\
\hline Total & & 64 & 74 & 13 & 15 & 10 & 11 & 87 \\
\hline
\end{tabular}




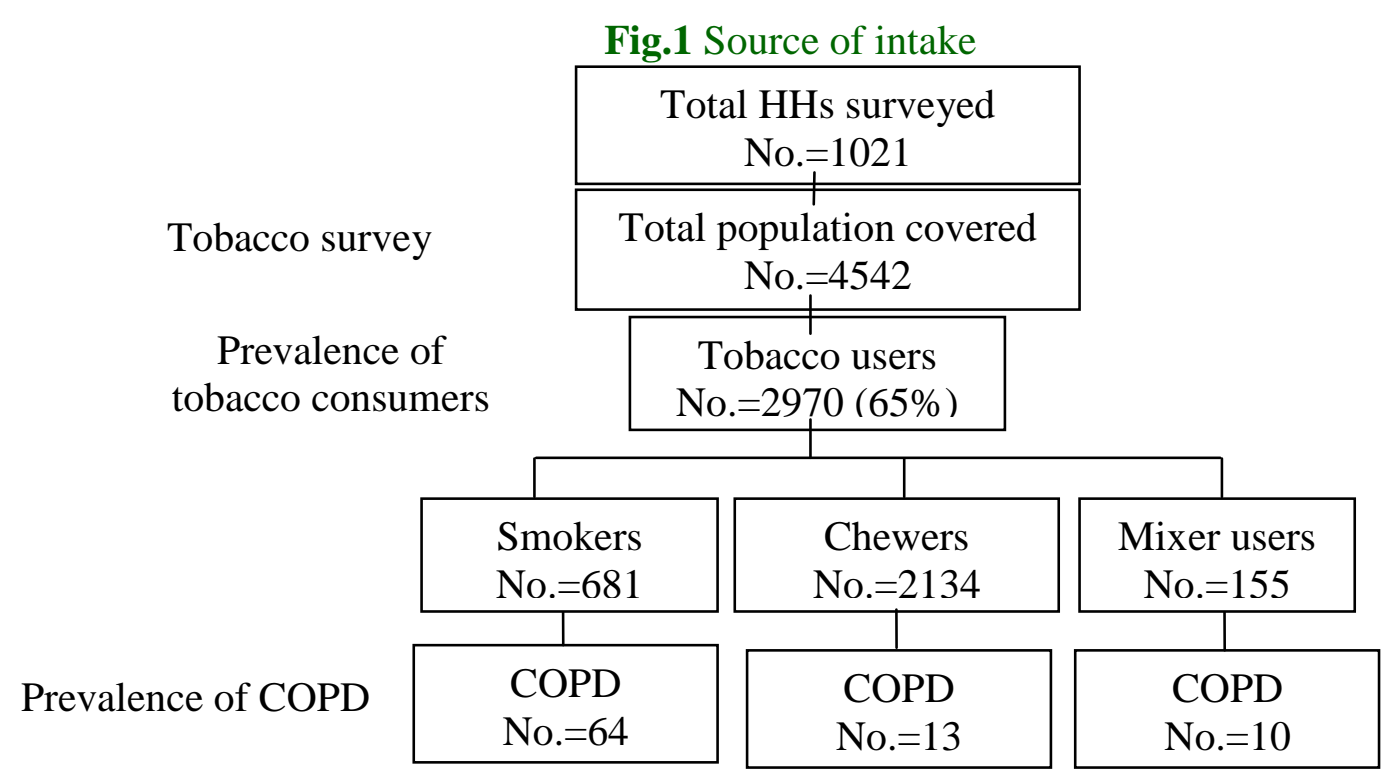

It still remains unrecognized epidemic in India, in particular among indigenous population. In general, nearly all tribes smoke tobacco in the form of bidis, which is locally made, cheap and easily available. It is estimated that bidis produce 4 to 5 times more tar than cigarettes despite one fourth the amount of nicotine, as compared to cigarette.

The current study reports a $9.4 \%$ prevalence of COPD among smokers. This rate is similar to prevalence reported by Jindal $e t$ al., (2006) among bidi smokers (8.2\%) (Jindal et al., 2006). It was reported that wide discrepancy in the prevalence rate of COPD exists across different studies. This may be due to use non-uniform and nonvalidated respiratory health questionnaires.

It was also pointed out that the estimates based on symptoms may be substantially lower than those based on spirometric measurements. Use of spirometry doubled the prevalence rate of COPD as compared to non use to define COPD. Most epidemiological studies in India use questionnaires based on respiratory symptoms. Here we have use both respiratory symptoms as well as stethoscope to identify wheezing or other abnormal chest sounds.

The present study is unique as it provides the prevalence of COPD among ethnic population dwelling in hard to reach areas. Many of the respondents have no access to health facilities for COPD diagnosis and treatment. Our study made an attempt to carry out active screening to diagnose COPD among tobacco users. All identified cases were counselled to quit smoking or use of tobacco, treated with basic medicines and referred to the nearest government health facility for further care and management. Smoking cessation is the most important step in the treatment of COPD and it is an effective tool to treat tobacco addiction (Vijayan, 2013). It has been reported that even a 3 minutes counseling to a smoker enables smoking cessation rates of 5 to $10 \%$ (Wilson, et al., 1990).

\section{Limitations of the study}

One factor that might be considered as a bias in this study is that data on female non- 
smokers is deficient and many female respondents were not willing to undergo medical examination. Another limitation of this study is the confirmation of COPD is based on clinical signs and symptoms; and only stethoscope was used as a diagnostic tool.

In conclusion, the current study provides the prevalence of COPD among Gond tribes and demonstrates that it is significantly higher among tobacco smokers. There is a need to take imminent action to provide smoking cessation to these vulnerable populations to control tobacco related diseases especially COPD. Most importantly efforts to educate the tribal population about the health hazards of smoking tobacco need to be taken up to improve their health.

\section{Acknowledgment}

We sincerely thank Director General, Indian Council of Medical Research (ICMR), New Delhi for her encouragement and constant support. We are grateful to Dr. Neeru Singh, Director, National Institute for Research in Tribal Health (ICMR), Jabalpur for her permission, encouragement, co-operation and continuous support. We thank the Block Medical Officer of Kundom Block for his cooperation. We also thank and acknowledge the project team members for their support on data collection, cleaning and entry. We also thank all the respondents for their co-operation for the interview. We sincerely thank the ICMR for providing necessary financial support.

\section{References}

Anderson, D., Ferris, B.G., Jr. 1962. Role of tobacco smoking in the causation of chronic respiratory disease. $N$. Engl. J. Med., 267: 787-94.
Jindal, S.K. 2012. COPD: The Unrecognized Epidemic in India. JAPI, 60: 14-16.

Jindal, S.K., Aggarwal, A.N., Chaudhry, K., Chhabra, S.K., D’Souza, G.A., Gupta, D., Katiyar, S.K., Kumar, R., Shah, B., Vijayan, V.K. 2006. A multicentric study on epidemiology of chronic obstructive pulmonary disease and its relationship with tobacco smoking and environmental tobacco smoke exposure. Indian J. Chest Dis. Allied Sci., 48: 23-29.

Murray, C.J.L., Lopez, A.D. 1997. Alternative projection of mortality and disability by cause 1990-2020: Global Burden of Disease Study. Lancet, 349: 1498-504.

Parvaiz, A.K. 2013. Chronic obstructive pulmonary disease: Indian guidelines and the road ahead. Lung India, 30(3): 175-177.

Singh, S., Soumya, M., Saini, A., Mittal, V., Singh, U.V., Singh, V. 2011. Breath carbon monoxide levels in different forms of smoking. Indian J. Chest Dis. Allied Sci., 53: 25-28.

Surendra Kumar, Dinesh Kumar, M., Muniyandi, V., Soan, Maya Pandey, D.K., Mishra. 2013. Poverty does not limit tobacco consumption among tribal population: Evidence from central India. Asian Pacific J. Cancer Prevention, 14(10): 6195-6196.

Vijayan, V.K. 2013. Chronic obstructive pulmonary disease. Indian J. Med. Res., 137: 251-269.

Wilson, D.H., Wakefield, M.A., Steven, I.D., Rohrsheim, R.A., Esterman, A.J., Graham, N.M. 1990. Sick of Smoking: evaluation of a targeted minimal smoking cessation intervention in general practice. Med. J. Aust., 152: 518-21.

World Health Organisation. Chronic respiratory diseases. 
http://www.who.int/respiratory/copd/d efinition/en/

http://www.who.int/respiratory/copd/b urden/en

World Health Organization. 2013. Burden

of COPD. Available from:

\section{How to cite this article:}

Surendra Kumar, M. Muniyandi, Dinesh Kumar, Maya Pandey, Visheshwar Soan and S. Rajasubramaniam. 2016. Chronic Obstructive Pulmonary Disease: Understanding and Promoting Healthy Lifestyle among Gond Tribe in Madhya Pradesh. Int.J.Curr.Microbiol.App.Sci. 5(10): 27-32. doi: http://dx.doi.org/10.20546/ijcmas.2016.510.005 